\title{
Searching for Early Developmental Activities Leading to Computational Thinking Skills
}

\author{
Quintin Cutts (leader), Peter Donaldson (co-leader) and Elizabeth Cole (co-leader) \\ University of Glasgow \\ United Kingdom \\ \{quintin.cutts, peter.donaldson.2\}@glasgow.ac.uk, e.cole.2@research.gla.ac.uk \\ Bedour Alshaigy \\ Oxford Brookes University \\ United Kingdom \\ bedour.alshaigy-2012@brookes.ac.uk \\ Edurne Larraza-Mendiluze
University of the Basque Country
Spain \\ edurne.larraza@ehu.eus \\ Mirela Gutica \\ British Columbia Institute of \\ Technology \\ Canada \\ mirela_gutica@bcit.ca \\ Robert McCartney \\ University of Connecticut \\ USA \\ robert.mccartney@uconn.edu \\ Charles Riedesel \\ University of Nebraska, Lincoln \\ USA \\ chuckr@unl.edu \\ Arto Hellas \\ University of Helsinki \\ Finland \\ arto.hellas@cs.helsinki.fi
Elizabeth Patitsas
University of Toronto \\ Canada \\ patitsas@cs.toronto.edu
}

\begin{abstract}
Drawing on the long debate about whether computer science (CS) and computational thinking skills are innate or learnable, this working group is based on the following hypothesis:

The apparent innate ability of some CS learners who succeed in CS courses despite no prior exposure to computing is a manifestation of early childhood experiences and learning outside formal education.
\end{abstract}

The key elements here are early experiences which are outside formal education that may be leading to success in CS courses, as these aspects have not been previously studied in detail.

Example experiences and learning are the kinds of toys played with, the encouragement given to explore, particular hobbies, exposure to different kinds of languages, and so on. An informal exercise with $16 \mathrm{CS}$ academics elicited the following potential pre-requisites from their own childhood experiences:

- Modelling, particularly when designing from scratch

- Autonomous devices from paper planes to steam engines

- Exposure to ad-hoc household fixing / repair processes

- Toys with discrete, not continuous, elements, e.g. Lego bricks, not smooth wooden blocks

- Interest in notations - music, languages (bi-lingual parents)

Permission to make digital or hard copies of all or part of this work for personal or classroom use is granted without fee provided that copies are not made or distributed for profit or commercial advantage and that copies bear this notice and the full citation on the first page. Copyrights for third-party components of this work must be honored. For all other uses, contact the Owner/Author. ITiCSE'17, July 03-05, 2017, Bologna, Italy

(C) 2017 Copyright is held by the owner/author(s).

ACM ISBN 978-1-4503-4704-4/17/07.

DOI: http://dx.doi.org/10.1145/3059009.3081332
- Parental attitudes encouraging open exploration, with minimal limits and permission to fail

- Following instructions: knitting, cooking, origami, Lego

- Making games - a set of rules

Consideration of the hypothesis leads to the following research questions:

1. Can we find activities that are relatively more common to the childhood experiences of those with CS skills, e.g. successful CS students, academics and professionals, by comparison with other members of the population?

2. If such activities can be determined, what common understanding, skills or attitudes can be derived from them?

3. Can the common aspects of the activities be linked to CS skills and therefore seen as pre-requisites?

4. In what ways are these common aspects already present in formal early years or primary education, and where they are not, how could they be incorporated effectively?

Studies supporting this hypothesis would be beneficial as follows:

- Provide further evidence against the innate view of CS skills, encouraging study of CS specific pedagogy.

- Inform educational practices and research in the early years, a field recognised as being of increasing importance.

- $\quad$ Enable early years and primary teachers with no formal CS background to focus on educational activities with which they are familiar and confident while still developing essential foundations for CT skills.

The primary focus of this working group is the first research question above. If this is answered positively, then we will work on preliminary answers to the subsequent questions. 